\title{
Polymorphs of Curcumin and its co-crystals with Cinnamic acid
}

\author{
Noopur Rathi*, Anant Paradkar ${ }^{\#}$ and Vilas G. Gaikar*
}

5

* Department of Chemical Engineering, Institute of Chemical Technology, Nathalal Parekh Marg, Matunga, Mumbai - 400019, India.

\# Professor of Pharmaceutical Engineering Science, Centre for Pharmaceutical Engineering Science, University of Bradford, Bradford, BD7 1DP, U.K.

Corresponding author Tel.: +91-022-33612013; fax: +91-022-33612013;

E-mail: vg.gaikar@ictmumbai.edu.in. 


\begin{abstract}
We report formation of polymorphs and new eutectics and co-crystals of curcumin, a sparingly water soluble active component in turmeric, with structurally similar cinnamic acid. The curcumin polymorphs were formed using liquid anti-solvent precipitation, where acetone acted as a solvent while water was used as the anti-solvent. The metastable Form 2 of curcumin was successfully prepared in varied morphology over a wide range of solvent to anti-solvent ratio and under acidic $\mathrm{pH}$ conditions.
\end{abstract}

We also report formation of new eutectics and co-crystals of curcumin with cinnamic acid acting as a co-former. The binary phase diagrams were studied using differential scanning calorimetry (DSC) that predict formation of the eutectics at the curcumin mole fraction of 0.15 and 0.33 , while a co-crystal is formed at 0.3 mole fraction of curcumin in the curcumin-cinnamic acid mixture. The formation of the co-crystal was supported with X-ray powder diffraction (p-XRD), the enthalpy of fusion values and Fourier Transform Infrared (FTIR) Spectroscopy and Scanning Electron Microscopy (SEM). The hydrogen bond interaction between curcumin and cinnamic acid is predicted from FTIR spectra, individually optimized curcumin and cinnamic acid structures by quantum mechanical calculations using Gaussion-09 and their respective unit cell packing structures.

Keywords: Curcumin; cinnamic acid; eutectic; co-crystal; polymorphs; anti-solvent 45 precipitation. 


\section{Introduction}

Curcumin, one of the major naturally active components of turmeric, shows a wide spectrum of biological and pharmacological activities which makes it a potential drug for treatment of various diseases. Despite its efficacy and pharmacological safety, the main limitation of curcumin-based formulations is poor water solubility of curcumin because of its poly-phenolic hydrophobic structure. Poor absorption and rapid metabolism adversely affect bioavailability of curcumin from the formulations. ${ }^{1-2}$

In order to increase its solubility, stability and pharmacological activity for optimum therapeutic effect, chemically modified curcumin derivatives as well as improved formulations and delivery systems are being studied..$^{3-7}$ Multiple approaches, including development of its analogues, liposomal and nanoparticle formulations, and crosslinking with other drugs, etc., are being developed to overcome these limitations. ${ }^{8-12}$

Formation of polymorphs, eutectics and co-crystals are other possible ways to overcome poor bioavailability of curcumin. Polymorphs of various drugs like carbamazepine, sulfamerazine, mefenamic acid, methylprednisolone, D-mannitol, etc., have been reviewed for decades and are well documented in literature. ${ }^{13-21}$ Curcumin reportedly shows three polymorphs of which the Form 1, the most common crystalline form of curcumin, is most stable. Amongst, the other two polymorphs of curcumin, Form 2 shows higher dissolution rate as compared to Form 1. The Form 3 of the curcumin, has been reported to be unstable and thus is difficult to reproduce. ${ }^{22}$ Liquid anti-solvent precipitation of curcumin to form different polymorphs with assistance of ultrasound and/or in the presence of different stabilizers has been reported recently. ${ }^{23,24}$

In recent years, studies of various co-crystals have become important, to provide a number of crystalline states of an Active Pharmaceutical Ingredient (API), in which physical 
and chemical properties such as solubility, stability and bioavailability, are enhanced without affecting the chemical composition of APIs. ${ }^{25}$ All the major co-crystals of the interest from pharmaceutical point of view have been reviewed recently, ${ }^{26}$ The formation of co-crystals seems to be an emerging field for enhancing specific properties of the APIs. ${ }^{27}$

Reports of co-crystal formation of curcumin or its eutectics with polyhydroxybenzenes, aromatic acids, amides, amines and amine oxides, have been listed well in the literature, with improved solubility and enhanced rates of solubilization of curcumin along with the coformers. ${ }^{28-30}$ The co-crystals of curcumin with resorcinol and pyrogallol show higher solubilization rates, 5 and 12 times, respectively, as compared to pure curcumin, in water. ${ }^{28}$ The intermolecular hydrogen bonding with the hydroxyl group of hydroxyquinol leads to formation of two different types of cocrystals with curcumin; one in 1:2 ratio showing a better dissolution rate as compared to another cocrystal formed in 1:1 ratio. Stronger intramolecular H-bonding interaction in salicylic acid, however, results in formation of an eutectic of the acid with curcumin. ${ }^{29}$ Recently, Katherine et. al. ${ }^{30}$ have reported formation of curcumin-dextrose co-crystals by solution crystallization where the dextrose concentration and temperature of the process affected the co-crystal formation. The curcumin-dextrose co-crystals also showed a remarkable solubility increase than curcumin alone, i.e. upto $2.5 \%$ in water. The solubility of curcumin in pure water is otherwise extremely low. Cocrystals of curcumin with Ibuprufen, naproxen, benzimidazole and lysine have been also reported. ${ }^{31,32}$ Although, most coformers forming co-crystals with curcumin 95 have aromatic structures, the coformers such as dextrose, piperazine and lysine defy the logic of necessity of existence of $\pi$ interactions to form the cocrystals. ${ }^{30-32}$ Apparently, the presence of either $-\mathrm{OH}$ or $\mathrm{NH}_{2}$ or a carbonyl group, is sufficient to form the cocrystals. The presence of $\pi$ interactions could be an additional advantage. 
Polymorphic Form 2 of curcumin has been proven to be more easily soluble than the commercially available Form 1 of curcumin. ${ }^{22}$ This paper reports a simpler method for formation of polymorphs of curcumin; particularly Form 2, using an anti-solvent precipitation method, over a range of solvent-to-anti-solvent ratio and under varying $\mathrm{pH}$ conditions.

We also report new eutectics and co-crystal of curcumin with cinnamic acid using a solid state grinding method. Cinnamic acid was chosen as a co-former for the co-crystal formation with curcumin as it is a natural analogue of curcumin because of the structural similarity. The encircled portion in the curcumin structure is similar to the structure of cinnamic acid.

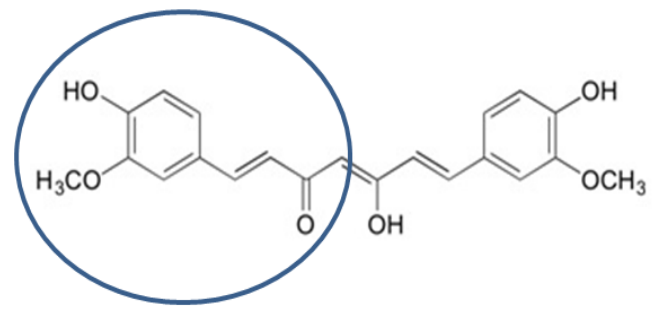

Curcumin

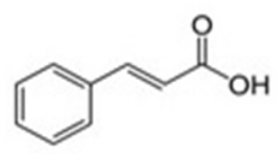

Cinnamic acid

Cinnamic acid is similar to one half of the basic curcumin skeleton structure. ${ }^{12}$ The types of hydrogen bonds and molecular aggregate formation within co-crystal components can be predicted by a few general rules. ${ }^{33-35}$ The acidic hydrogen in cinnamic acid helps in $\mathrm{H}-$ bonding with the phenolic $-\mathrm{OH}$ groups of curcumin that act as hydrogen bond acceptors. Cinnamic acid and its derivatives are also known to possess hepatoprotective, antioxidant and anti-cancer activities and would add value in therapeutic applications of curcumin in the API formulations. $^{36-38}$ The binary phase diagram for curcumin and cinnamic acid system is further studied in detail to define the eutectic and the co-crystal regions. 


\section{Experimental section}

\section{Materials}

Curcumin (>95\%) was procured from Sigma-Aldrich. Acetone (99.5\% pure), methanol $(\geq 99.8 \%)$, ethanol $(\geq 99.8 \%)$, acetonitrile $(\geq 99.93 \%)$, hydrochloric acid $(37 \%)$ and potassium chloride ( $\geq 99 \%$ ) were also purchased from Sigma-Aldrich. Cinnamic acid (99.5\% pure) was purchased from Molychem, Mumbai. De-ionised water from Milli Q system was used for all the experiments.

\section{Methods}

Polymorphic studies of Curcumin by anti-solvent method

A stock solution of curcumin was first prepared in acetone $\left(500 \mathrm{mg} \mathrm{dm}^{-3}\right)$. In a typical experiment, a known volume of the curcumin solution in acetone was added to a known volume of water, an anti-solvent. For example, for preparing a solution mixture of 1:10 solvent-to-anti-solvent ratio, $1 \mathrm{~cm}^{3}$ of the stock solution of curcumin in acetone was added to a beaker containing $10 \mathrm{~cm}^{3}$ of water under stirred conditions, both maintained at a constant temperature of $30^{\circ} \mathrm{C}$ in a water bath. Immediate precipitation was seen on the addition of the curcumin solution. The suspension was vacuum filtered (using Whatman filter paper, grade 50) after 2 min to recover the precipitated curcumin. The solid was kept in open for air drying at room temperature for several hours, till it formed a dry and free flowing powder. The final powder was used for analysis by different techniques. The same procedure was repeated for 2:10, 3:10, 4:10 and 5:10, solvent-to-anti-solvent ratios in exactly the same manner.

In another set of experiments, for varying the anti-solvent to solvent ratio, varying volumes of water $\left(4,6\right.$ and $\left.8 \mathrm{~cm}^{3}\right)$ were poured into beaker containing a fixed amount $\left(1 \mathrm{~cm}^{3}\right)$ of the stock solution of curcumin in acetone to form 1:4, 1:6 and 1:8 solvent-to-anti-solvent ratios in the final mixture. 
Experiments were conducted by varying the $\mathrm{pH}$ of the anti-solvent from 1.5 to 5 using a buffer system of hydrochloric acid and potassium chloride with ionic strength of $0.1 \mathrm{M}$ $0.15 \mathrm{M}$.

All the solid samples were analysed by differential scanning calorimetry (DSC) using a Simultaneous Thermal Analyser (STA) Perkin Elmer 6000 apparatus. X-ray powder diffraction (p-XRD) pattern of the samples was analysed using a Bruker D8 diffractometer (X-ray wavelength $-0.154 \mathrm{~nm}$, source $-\mathrm{Cu}$, voltage $-40 \mathrm{kV}$ and filament emission -40 $\mathrm{mA}$ ). All samples were scanned for $2 \theta$ values from 2 to $30^{\circ}$ with $0.01^{\circ}$ step width. A

Scanning Electron Microscopy (SEM) using JEOL, (JSM-638OLA, Japan) Electron Scanning Microscope, was used for checking the morphology of the solid samples. All the above experiments were performed twice.

Eutectics and Co-crystals of Curcumin with Cinnamic Acid

The binary phase diagram studies were conducted using differential thermal analysis for determining the molar ratio of curcumin to cinnamic acid at which the eutectics or cocrystals are formed. This method is a high-performance screening system, particularly for APIs with low solubility and/or propensity to form solvates. ${ }^{42}$

Ten samples of physical mixtures of curcumin and cinnamic acid covering the entire composition range were prepared by solid state grinding of the mixture for about $5 \mathrm{~min}$ in a mortar using pestle without any solvent. These physical mixtures were analysed on DSC.

The mixture of curcumin and cinnamic acid, at a molar ratio that shows formation of a co-crystal (as obtained from the binary phase diagram) was completely dissolved in the solvents such as acetone, ethanol, methanol and acetonitrile. The solvent was then allowed to evaporate slowly and completely at $30{ }^{\circ} \mathrm{C}$ to form crystals. The solid product so obtained was analysed by DSC, p-XRD and SEM. Fourier Transform Infra-Red spectra (FTIR) of the samples, as $\mathrm{KBr}$ pellets, were recorded on a Bruker-VERTEX 80V instrument, in absorbance 
mode with 128 scans with resolution of $1 \mathrm{~cm}^{-1}$. All the above experimental runs were performed in duplicates.

\section{Results and Discussion}

Solubility of curcumin in acetone is stated to be greater than $2(w / w \%){ }^{39}$ but it is less than $5 \mu \mathrm{M}$ in water at the ambient temperature of $30^{\circ} \mathrm{C}^{40,41}$. Therefore, acetone was chosen as good solvent while water acts as an anti-solvent. However, no data on solubility of curcumin in the water + acetone mixtures at different weight ratios are available. But it is clear that pure water shows an extremely low solubility of curcumin and thus the entire amount of curcumin can be precipitated by addition of water as anti-solvent to solutions of curcumin in acetone.

The DSC plots in Figure 1 (a) and (b) show the effect of solvent-to-anti-solvent ratio on curcumin precipitation; where, the volume of the solvent is increased keeping the volume of the anti-solvent constant and when volume of the anti-solvent is increased keeping the volume of the solvent constant, respectively. In Figure 1 (a), an endothermic peak at $174{ }^{\circ} \mathrm{C}$ corresponds to the melting point of a polymorph of curcumin (Form 2$)^{22}$, which is seen to be followed by re-crystallization of this polymorph at $179{ }^{\circ} \mathrm{C}$ followed by melting, giving the second endotherm at around $184^{\circ} \mathrm{C}$ (Form 1). The low temperature endotherm followed by melting and re-crystallization is the characteristic of a metastable polymorph ${ }^{17}$; here, the Form 2 of curcumin. Each plot with varying solvent-to-anti-solvent ratio shows similar characteristics confirming the formation of the polymorph over the entire range of solvent composition.

Figure 2 shows p-XRD spectra of curcumin obtained by varying the solvent-to-antisolvent ratio. The Form 2 of curcumin has a characteristic peak at $2 \theta$ of $14^{\circ}$ while the absence of this peak at $2 \theta$ of $14^{\circ}$ and occurrence of additional smaller peaks at $2 \theta$ of $26^{\circ}$ and 
$27^{\circ}$ show the presence of Form 1 of curcumin. ${ }^{22}$ Although the polymorphic Form 2 is formed at various solvent to anti-solvent ratio, the $\mathrm{p}$-XRD peaks show a significant loss in the crystallinity than the pure curcumin in Form 1.

For the solvent ratios of 3:10 and 5:10, however, the p-XRD spectra show a sharp peak at $2 \theta$ of $14^{\circ}$ with the absence of the peaks at $26^{\circ}$ and $27^{\circ}$, indicating precipitation of pure Form 2 of curcumin. The increase in the solvent-to-anti-solvent ratio leads to higher solubility of curcumin Form 1, precipitating Form 2 alone. Form 2 is more likely to precipitate being unstable than Form $1 .{ }^{22}$

From the DSC and p-XRD results for varying solvent: anti-solvent ratios (Figures 1 and 2), solvent-to-anti-solvent ratio of 3:10 showed the presence of pure Form 2 of curcumin. Hence, for varying $\mathrm{pH}$ conditions of anti-solvent, this ratio was selected. The DSC and p$\mathrm{XRD}$ analyses were performed on the solids obtained by the varying $\mathrm{pH}$ of the anti-solvent in the acidic range.

The DSC plots in Figure 3 (a) indicate that at lower $\mathrm{pH}$ values ranging between 1 and 3 , the metastable Form 2 polymorph is still formed, while at the $\mathrm{pH}$ of the anti-solvent, higher than 3, this Form 2 of curcumin is not seen at all. The reason can be due to the higher stability of curcumin at lower $\mathrm{pH}$ conditions. ${ }^{43}$ This results in the precipitation of both the forms of curcumin i.e. Form 1 and Form 2 together. At pH higher than 3, Form 1, which has 210 a lower solubility; precipitates without Form $2 .^{22}$ There is a possibility of phase transformation of Form 2 to Form 1 at $\mathrm{pH}$ above 3, leading to the precipitation of Form 1 alone. $^{44}$

The p-XRD spectra in Figure $3(b)$ are for polymorphs of curcumin precipitated by varying $\mathrm{pH}$ of the anti-solvent at 3:10 solvent-to-anti-solvent ratio. Similar to DSC, it 215 indicates the presence of pure Form 1 of curcumin at $\mathrm{pH}$ conditions above 3; while at a $\mathrm{pH}$ lower than 3, mixture of both the forms, Form 1 and Form 2 of curcumin precipitate. Thus, in 
a range of varying the solvent-to-anti-solvent ratio and the $\mathrm{pH}$ of the anti-solvent lower than 3, the metastable Form 2 of curcumin can be formed easily.

The SEM images of the curcumin polymorphs suggest a wide variation in morphology with varying the solvent-to-anti-solvent ratio and the $\mathrm{pH}$ of the system. Figure 4 $(a-f)$ are the SEM images of the polymorphs for increasing solvent-to-anti-solvent ratio from 1:10 to 1:2. The crystals agglomerate to form bigger clusters as seen for solvent-to-antisolvent ratio of 1:10 in Figure $4(b)$. At a low solvent-anti-solvent ratio, the supersaturation increases drastically due to decrease in the solubility of curcumin, resulting into precipitation of a large number of smaller spherical aggregates. (One such aggregate is shown in Figure 4 (b)) With increase in solvent-to-anti-solvent ratio to 2:10 (Figure 4(c)), the slight decrease in the supersaturation leads to precipitation of particles in a non-spherical agglomerate. The solubilization and precipitation compete with increasing the solvent content of the solutions. The spherical aggregate structure of curcumin crystals at lower solvent-to-anti-solvent ratio, changes to fine needle- like crystals at 3:10 solvent to anti-solvent ratio. At this ratio, the crystals are fiber like, which are loosely but regularly connected to form a mesh like structure (Figure $4(d)$ ). The increase in acetone content in the mixed solvents lowers degree of supersaturation and favors more solubilization of curcumin, resulting in the slow precipitation of the crystals, consequently maintaining supersaturation and hence affecting the growth rates of the crystals. At 4:10 solvent-to-anti-solvent ratio, an excess of solvent increases the solubility of curcumin, that makes curcumin difficult to precipitate or growth of the already precipitated solids. The fibers are no longer dominant and the morphology turns to smaller and finer particles (Figure $4(e)$ ). This suggests that a polymorph exhibits a nano-mesh like structure only at a particular solvent-to-antisolvent ratio of 3:10 and the structure transforms to agglomerates and fine crystals both below and above this ratio. 
The SEM images of changing morphologies of curcumin crystals with increase in antisolvent content, in the solution are shown in Figure $4(f-i)$. Addition of water initially increases supersaturation; favoring precipitation of curcumin particles in agglomerate form with plate like morphologies as in case of 1:2 and 1:4 solvent-to-anti-solvent ratios. (Figure 4 $h, g$ ) For the cases of 1:6 and 1:8 ratio i.e. with further increase in the anti-solvent content, the supersaturation increases significantly resulting in lower solubility of curcumin and hence favoring rapid precipitation of a larger number of smaller crystals leading to formation of an aggregate with a random morphology. (Figure $4(h, i))$

For the 3:10 solvent-to-antisolvent ratio, the $\mathrm{pH}$ of 1.5 of water shows two different morphologies, plate like and aggregates, while that for $\mathrm{pH} 2.3$, it changed to amorphous aggregates (Figures $5 a, b$ ). These structures suggest that at $\mathrm{pH} 1.5$, two different polymorphs are present together, while increase in $\mathrm{pH}$ tends to precipitation of amorphous solid as also confirmed by $\mathrm{p}$-XRD peaks as seen in Figure $3 b$.

The experiments in duplication were also done, where all the samples which were analysed for DSC and p-XRD showed peaks in the similar range and the SEM showed a morphological difference corresponding to $\pm 0.5 \mu \mathrm{m}$.

Eutectics and Co-crystals of Curcumin - cinnamic acid: Binary phase diagram studies

Few reports are available on formation of co-crystal and eutectics and their structural inter-relationships based on the phase solubility diagrams. ${ }^{47,48}$ To understand the region of cocrystal formation, the binary phase diagram for the system of curcumin and cinnamic acid is developed further. The Differential Scanning Calorimetry (DSC) plots for varying mole fraction of curcumin in the mixture are shown in Figure 6. The phase diagram was plotted by plotting solidus (onset temperature for the first peak) and liquidus (peak temperature of the second peak) temperatures from all the DSC curves. (Figure 7) This gives an idea of curcumin mole fraction at which the co-crystal forms and the temperature till which it will be 
stable. It was observed that the systems with the curcumin mole fraction of 0.15 and 0.33 form the eutectics, $E_{1}$ and $E_{2}$, respectively, while, the system with curcumin mole fraction of 0.3 , forms a co-crystal.

The mixture with the curcumin mole fraction of 0.3 was then further dissolved completely in various solvents such as acetone, ethanol, methanol and acetonitrile to obtain single crystals. But the single crystals which are suitable for the single crystal XRD analysis were not obtained from any of the solvent systems. Out of all the systems, crystallization carried out by evaporative crystallization from acetone followed by complete drying at $30{ }^{\circ} \mathrm{C}$ resulted in co-crystals and both the eutectics. The powder thus obtained was analysed further by DSC, p-XRD, FTIR and SEM.

Figure $8(a)$ shows comparison of the endothermal peaks for curcumin-cinnamic acid systems with $0.15,0.3$ and 0.33 mole fractions of curcumin in the mixtures, obtained after recrystallization in acetone. In the mixture of curcumin and cinnamic acid, containing 0.15 mole fraction of the curcumin, there is only one endothermic peak at around $129^{\circ} \mathrm{C}$ suggesting the formation of an eutectic. For 0.3 mole fraction of curcumin in the mixture, an endothermal peak onset at $112^{\circ} \mathrm{C}$ and another peak is seen at $123{ }^{\circ} \mathrm{C}$. This peak corresponds to the formation of a co-crystal as further evidenced by additional crystalline structure reflected in the p-XRD studies. For 0.33 mole fraction of curcumin in the mixtures with cinnamic acid, the first endothermic peak appears at $127^{\circ} \mathrm{C}$ which corresponds to the eutectic melting, which is very near to the eutectic melting of $129^{\circ} \mathrm{C}$, as observed for the 0.15 mole fraction of curcumin in the mixture. It is followed by the second endothermic peak at $141{ }^{\circ} \mathrm{C}$, which is ascribed to the melting of the curcumin along with its co-crystal. ${ }^{42}$

The p-XRD (Figure $8(b)$ ) suggests that, the pattern for the mixture containing curcumin mole fraction of 0.15 remains more or less similar to those of the parent compounds. For the mixture having curcumin mole fraction of 0.33 forming eutectic $\mathrm{E}_{2}$, the 
p-XRD shows new and major characteristic peaks at $2 \theta$ of $11.11^{\circ}, 12.15^{\circ}, 14.47^{\circ}, 15.69^{\circ}$ and $23.55^{\circ}$. Therefore, by analyzing the results of DSC and p-XRD together, one can suggest that the mixture of curcumin and cinnamic acid with 0.15 mole fraction of curcumin forms an eutectic $E_{1}$, at 0.3 mole fraction of curcumin it forms a co-crystal and at 0.33 mole fraction of curcumin, the mixture forms another eutectic $\mathrm{E}_{2}$ along with the co-crystal.

The experimental values of enthalpy $\left(\Delta H_{\text {experimental }}\right)$ were obtained from the DSC software itself. The enthalpy of fusion values were calculated using the mixture law ${ }^{41}$, as given by Eq. (1),

$$
\Delta H_{\text {calc }}=x_{1} \Delta H_{1}+x_{2} \Delta H_{2}
$$

where, $\Delta H_{\text {calc }}$ is the total enthalpy of fusion for a system comprising of the components $l$ and 2, $x_{1}$ and $x_{2}$ are the respective mole fractions of the components present in the system with the individual enthalpies of fusion values (for pure components curcumin and cinnamic acid obtained from the DSC graphs) given by $\Delta H_{1}$ and $\Delta H_{2}$. The values obtained thus are given in Table 1. The experimentally determined values are lower than the calculated values for the eutectics as well as for co-crystals, indicating the presence of interaction between curcumin and cinnamic acid. Also, the enthalpy values of curcumin and cinnamic acid individually, are higher than those of the eutectics $\mathrm{E}_{1}, \mathrm{E}_{2}$ and co-crystal. This suggests stronger intra-molecular interactions within pure components molecules than the molecular interactions present in the eutectic or the co-crystal. $^{45}$

The electrostatic charge distribution of individual molecules of curcumin and cinnamic acid (Figure $9(a)$ and $(c)$ ) was obtained by Gaussian-09 software, using density functional theory (DFT) calculations with B3LYP functional and 6-311++G $(d, p)$ basis set without any constraints. ${ }^{45}$ Also, the crystal packing structures of the individual molecules of curcumin and 315 cinnamic acid (Figure $9(b, d)$ ) were obtained by Mercury software(version 3.10) ${ }^{46}$, to study 
possible intermolecular and intramolecular hydrogen bonding combinations. Out of the three hydroxyl groups in curcumin, the phenolic hydroxyl groups with the oxygen atom having electrostatic charges $(-0.491$ and -0.482$)$ are more susceptible to hydrogen bonding than the oxygen atom present in the -enol group which has an electrostatic charge of -0.411. (Figure 9 (a)) While the cinnamic acid shows no intramolecular $\mathrm{H}$-bonding, the acidic $-\mathrm{OH}$ group functions as both, H-bond donor and acceptor. (Figure $9(d)$ ) These figures show the possibility of formation of hydrogen bond between the carbonyl $=\mathrm{O}$ (with electrostatic charge of -0.389 ) of cinnamic acid with the phenolic $-\mathrm{OH}$ of the curcumin to form a co-crystal.

In the FTIR spectra (Figure S1) of eutectics and co-crystal of curcumin and cinnamic acid with individual pure components, at $3510 \mathrm{~cm}^{-1}$ in curcumin, characteristic symmetric stretching peak of $-\mathrm{OH}$ shows a shift to $3517 \mathrm{~cm}^{-1}$ for the 0.3 curcumin: cinnamic acid cocrystal. While that for the eutecics $E_{1}$ and $E_{2}$ the same peaks are at $3513 \mathrm{~cm}^{-1}$ and $3519 \mathrm{~cm}^{-1}$ respectively. This increased frequency suggests that the $-\mathrm{OH}$ group of curcumin is involved in $\mathrm{H}$-bond formation with carbonyl $=\mathrm{O}$ of cinnamic acid. Disappearance of the characteristic broad peak of carboxylic $-\mathrm{OH}$ stretching at $3000 \mathrm{~cm}^{-1}$ in cinnamic acid and smaller and sharper peaks appearing in the eutectics and the co-crystal around $3069 \mathrm{~cm}^{-1}$ suggests the involvement of the carboxylic acid's $-\mathrm{OH}$ group in H-bond formation. However, the carbonyl stretching frequency which occurs at around $1685 \mathrm{~cm}^{-1}$ cinnamic acid, shows a shift to lower frequency at around $1675 \mathrm{~cm}^{-1}$ indicating conjugation of this $\mathrm{C}=\mathrm{O}$ group, probably due to the intermolecular $\mathrm{H}$-bonding. $\mathrm{C}-\mathrm{O}-\mathrm{H}$ bending frequencies, which occurs at $1429 \mathrm{~cm}^{-1}$ for curcumin shows a slight shift to $1426 \mathrm{~cm}^{-1}$ and $1424 \mathrm{~cm}^{-1}$ for a co-crystal and eutectic $\mathrm{E}_{1}$. Table 2 lists out the various major peaks from the FTIR spectra.

From the spectral changes observed in FTIR studies (Table 2) and the optimised crystal structures with the electrostatic charges on the indivudual atom and also the packing 
structures of these individual molecules (Figure $9(a-d)$ ), probable interaction between these two molecules in their co-crystal was predicted as shown in Figure $9(e)$. The H-bonding occurs between the $\mathrm{C}=\mathrm{O}$ group of cinnamic acid with the $-\mathrm{OH}$ group of curcumin in an axial direction, with the phenolic groups of curcumin and cinnamic acid are showing a slight shift in the plane beacuse of the $\pi$ - $\pi$ stacking interactions.

Figure 10 ( $a$-e) shows the SEM images of curcumin, cinnamic acid, 0.3 curcumin: cinnamic acid co-crystal and the eutectics $E_{1}$ and $E_{2}$. While pure curcumin seems to have random and variant sizes of the crystals, having different geometries; cinnamic acid has flat plate like structures. The co-crystals can be seen to be of a distorted oval morphology, with slightly porous nature (Figure $10(d)$ ) as compared to that of parent crystals which are comparatively non-porous. Improved porosity could mean higher surface area and hence better solubility rate of the co-crystal. ${ }^{49}$ Eutectics $E_{1}$ and $E_{2}$ both have varied morphology ranging from small powder like to bigger crystals (Figure $10(c, e)$ ). These studies indicate that co-crystal of curcumin with cinnamic acid at the mole fraction of 0.3 of curcumin, i.e. in almost 1:2 molar ratios may lead to better solubilization rate than curcumin alone. Further studies, however, need to be performed to obtain single crystals of this co-crystal, which will lead to dissolution studies necessary for its possible utilization in the field of pharmaceuticals.

\section{Conclusion}

Polymorph of curcumin, i.e. Form 2 was successfully prepared by an anti-solvent precipitation technique over a wide range of solvent: anti-solvent ratios and also under varying $\mathrm{pH}$ conditions. The solvent-to-anti-solvent ratio plays an important role in deciding the final morphology of the polymorph and the 3:10 solvent-to-anti-solvent ratio resulted in nano-precipitation of curcumin in a regular wire mesh like structure.

For the binary system of curcumin and cinnamic acid, the phase diagram studies successfully showed the presence of eutectics $E_{1}$ and $E_{2}$ at the ratios of 0.15 and 0.33 of 
curcumin mole fraction and the presence of a co-crystal at the curcumin mole fraction of 0.3 . The analytical methods prove the formation of the cocrystal. With the help of electrostatic charges present on the optimized atoms along with the FTIR spectra, the possibility of hydrogen bond formation between curcumin and cinnamic acid in their co-crystal is presented. This co-crystal may have a possible application in the field of medicines because of the anti-oxidant and anti-cancer properties of cinnamic acid in addition to those of curcumin.

\section{Acknowledgement}

We are thankful to UKIERI (UK-India Education and Research Innovative) project entitled "Process analytics enabled green technologies for processing of poorly soluble drugs" funded by British Council, India. The project was done at the Centre for Pharmaceutical Engineering Science of Bradford, University of Bradford, UK and the Institute of Chemical Technology, Mumbai, India

\section{References}

1. Paradkar, A.; Kunnumakkara, A. B.; Newman, R. A. and Aggarwal, B. B. Bioavailability of curcumin: problems and promises, Mol. Pharma. 2007, 4(6), 807 -818.

2. Liu, W., Zhai, Y., Heng, X., Che, F. Y., Chen, W., Sun, D. and Zhai, G. Oral bioavailability of curcumin: problems and advancements J. Drug Target. 2016, 24(8), 694- 702.

3. Jin, D., Lee, J. H., Seo, M. L., Jaworski, J. and Jung, J. H. Controlled drug delivery from mesoporous silica using a pH-response release system New J. Chem. 2012, 36, 16161620.

4. Paradkar, A., Ambike, A. A., Jadhav, B. K., Mahadik, K.R. Characterization of curcumin-PVP solid dispersion obtained by spray drying Int. J. Pharma. 2004, 271, 281286. 
5. Prasad, S. Tyagi, A. K. and Aggarwal, B. B. Recent Developments in Delivery, Bioavailability, Absorption and Metabolism of Curcumin: the Golden Pigment from Golden Spice Cancer Res.Treat. 2014, 46(1), 2-18.

6. Ohori, H., Yamakoshi, H., Tomizawa, M., Shibuya, M., Kakudo, Y., Takahashi, A., Takahashi, S., Kato, S., Suzuki, T., Ishioka, C., Iwabuchi, Y. and Shibata, H. Synthesis and biological analysis of new curcumin analogues bearing an enhanced potential for the medicinal treatment of cancer Mol. Cancer Ther. 2006, 5(10), 2563- 2571.

7. Mulik, R. S., Mönkkönen, J., Juvonen, R. O., Mahadik, K. R., Paradkar, A. R. Transferrin mediated solid lipid nanoparticles containing curcumin: Enhanced in vitro anticancer activity by induction of apoptosis Int. J. Pharma. 2010, 398, 190-203.

400 8. Hasan, M.; Belhaj, N.; Benachour, H.; Barberi-Heyob, M.; Kahn, C. J. F.; Jabbari, E.; Linder, M.; Arab-Tehrany, E.; Liposome encapsulation of curcumin: Physico-chemical characterizations and effects on MCF7 cancer cell proliferation Int. J. Pharma. 2014, 461, $519-528$.

9. Cheng, C.; Peng, S.; Li, Z.; Zou, L.; Liu, W. and Liu, C. Improved bioavailability of curcumin in liposomes prepared using a $\mathrm{pH}$-driven, organic solvent-free, easily scalable process $R S C A d v .$, 2017, 7, 25978-25986.

10. Bhawana; Basniwal, R. K.; Buttar, H. S.; Jain, V. K. and Jain, N. Curcumin Nanoparticles: Preparation, Characterization, and Antimicrobial Study J. Agric. Food Chem. 2011, 59, 2056-2061.

410 11. Pandit, R. S.; Gaikwad, S. C.; Agarkar, G. A.; Gade, A. K. and Rai, M. Curcumin nanoparticles: physico-chemical fabrication and its in-vitro efficacy against human pathogens 3, Biotech 2015, 5, 991-997.

12. Anand, P.; Thomas, S. G.; Kunnumakkara, A. B.; Sundaram, C.; Harikumar, K. B.; Sung, B.; Tharakan, S. T. ; Misra, K.; Priyadarsini, I. K.; Rajasekharan, K. N.; Aggarwal, 
B. B. Biological activities of curcumin and its analogues (Congeners) made by man and Mother Nature Biochem. Pharmacol. 2008, 76, 1590 - 1611

13. Borka, L. and Haleblian, J. K., Crystal polymorphism of pharmaceuticals Acta Pharaceutica Jugoslavica 1990, 40, 71-94.

14. Threlfall, T. L. Analysis of Organic Polymorphs, Analyst 1995, 120, 2435-2460.

15. Bernstein, J.; Davey, R. J. and Henck, J. O. Concomitant Polymorphs Angew. Chem. Int. Ed. 1999, 38, 3440-3461.

16. Dunitz, J. D. and Bernstein, J. Disappearing Polymorphs, Acc. Chem. Res. 1995, 28, 193200.

17. Grzesiak, A. L.; Lang, M.; Kim, K. and Matzger, A. J. Comparison of the Four Anhydrous Polymorphs of Carbamazepine and the Crystal Structure of Form I, J. Pharm. Sci., 92(11), 2003, 2260- 2271.

18. Zhang, G. G.; Gu, C.; Zell, M. T.; Burkhardt, R. T.; Munson, E. J. and Grant, D. J., Crystallization and transitions of sulfamerazine polymorphs, J. Pharm. Sci. 2002, 91(4),1089-100.

430 19. Cesur, S. and Gokbel, S. Crystallization of mefenamic acid and polymorphs, Cryst. Res. Technol. 2008, 43(7), $720-728$.

20. Higuchi, W. I.; Lau, P. K.; Higuchi, T.; Shell, J. W. Polymorphism and drug availability. Solubility relationships in the methylprednisolone system J. Pharm. Sci. 1963, 52(2), $150-153$.

21. Burger, A.; Henck, J. O.; Hetz, S.; Rollinger, J. M.; Weissnicht, A. A. and Stottner, H. Energy/temperature diagram and compression behaviour of the polymorphs of DMannitol, J. Pharm. Sci. 2000, 89(4), 457-468.

22. Sanphui, P.; Goud, N. R.; Rao Khandavilli, U. B.; Bhanoth, S. and Nangia, A., New polymorphs of curcumin Chem. Comm. 2011, 47, 5013-5015. 
23. Thorat, A. A. and Dalvi, S. V. Particle formation pathways and polymorphism of curcumin induced by ultrasound and additives during liquid antisolvent precipitation Cryst. Eng. Comm. 2014, 16, 11102.

24. Thorat, A. A. and Dalvi, S. V. Ultrasound-assisted modulation of concomitant polymorphism of curcumin during liquid antisolvent precipitation Ultrason. Sonochem. 2016, 30, 35-43.

25. Chadha, R., Saini, A., Arora, P. and Bhandari, S. Pharmaceutical co-crystals: A novel approach for oral bioavailability enhancement of drugs Crit. Rev. Ther. Drug Carrier Syst. 2012, 29, 3.

26. Brittain, H. G. Cocrystal Systems of Pharmaceutical Interest: 2011 Cryst. Growth Des. 2012, $12,5823-5832$.

27. Nanjwade, V. K.; Manvi, F. V.; Shamrez, A. M.; Nanjwade, B. K. and Maste, M. M. New Trends in the Co-crystallization of Active Pharmaceutical Ingredients J. App. Pharm. Sci. 2011, $1(8), 1-5$

28. Sanphui, P.; Goud, N. R.; Rao Khandavilli, U. B. and Nangia, A. Fast dissolving curcumin co-crystals Cryst. Growth Des. 2011, 11, 4135-4145.

29. Sathisaran, I. and Dalvi, S. V. Crystal engineering of curcumin with salicylic acid and hydroxyquinol as coformers, Cryst. Growth Des. 2017, 17, 3974-3988.

30. Katherine, Nugroho, D. and Sugih, A. K. Determination of process parameters for curcumin - dextrose cocrystallization IOP Conference Series: Mat. Sci. Engg. 2018, 299, 012038.

31. Chava, S., Gorantla, S. R. A. and Muppidi, V. K. inventors; Laurus Labs Private Limited, assignee, Solid forms of curcumin and derivatives thereof, W02015052568A3, 2015, June 18. 
32. Gately, S. T., Triezenberg, S. J. and Wang, T. inventors; Van Andel Research Institute Translational Genomics Research Institute (TGen), assignee, Solid forms of curcumin, US9447050B2, 2016, September 20

33. Donohue, J. The hydrogen bond in organic crystals, J. Phys. Chem. -Us 1952, 56 (4), $502-510$.

34. Etter, M. C. Encoding and decoding hydrogen-bond patterns of organic compounds, Acc. Chem. Res. 1990, 23, 120-126.

35. Etter, M. C. Hydrogen bonds as design elements in organic chemistry, J. Phys. Chem.-Us 1991, 95, 4601-4610.

36. Lee, E. J.; Kim, S. R.; Kim, J.; Kim, Y. C. Hepatoprotective phenylpropanoids from Scrophularia buergeriana roots against CCl4-induced toxicity: Action mechanism and structure-activity relationship, Planta. Med. 2002, 68, 407-411.

37. Natella, F.; Nardini, M.; Di Felice, M. and Scaccini, C. Benzoic and cinnamic acid derivatives as antioxidants: structure-activity relation, J. Agric. Food. Chem. 1999, 47, 1453-1459.

38. Niero, E. L. and Machado-Santelli, G. M. Cinnamic acid induces apoptotic cell death and cytoskeleton disruption in human melanoma cells, J. Exp. Clin. Cancer Res. 2013, 32, 3145.

39. Cayman Chemical Company, USA, Product information, Curcumin (technical grade) item no. 81025.1, 2012.

40. Kim, M. K., Mok, H. and Chong, Y. Increased Water Solubility of the Curcumin Derivatives via Substitution with an Acetoxy Group at the Central Methylene Moiety, Bull. Korean Chem. Soc. 2012, 33 (9), 2849-2850. 
41. Kurien, B. T., Singh, A., Matsumoto, H. and Scofield, R. H. Improving the solubility and pharmacological efficacy of curcumin by heat treatment, ASSAY and Drug Dev. Tech. 2007, 5(4), 567-576.

42. Yamashita H.; Yutaka, H.; Yuda, M. and Terada, K. Coformer screening using thermal analysis based on binary phase diagrams, Pharm. Res. 2014, 31, 1946-1957

43. Wang, Y. J.; Pan, M. H.; Cheng, A. L.; Lin, L. L.; Ho, Y. S.; Hsieh, C. Y. and Lin, J. K. Stability of curcumin in buffer solutions and characterization of its degradation products, J. Pharm. Biomed. Anal. 1997, 15, 1867- 1876.

44. Thorat, A. A. and Dalvi, S. V. Solid-State Phase Transformations and Storage Stability of Curcumin Polymorphs Cryst. Growth Des. 2015, 15 (4), 1757-1770.

45. Frisch, M.J., Trucks, G.W., Schlegel, H.B., Scuseria, G.E., Robb, M.A., Cheeseman, J.R., Scalmani, G., Barone, V., Mennucci, B., Petersson, G.A., Nakatsuji, H., Caricato, M., Li, X., Hratchian, H.P., Izmaylov, A.F., Bloino, J., Zheng, G., Sonnenberg, J.L., Hada, M., Ehara, M., Toyota, K., Fukuda, R., Hasegawa, J., Ishida, M., Nakajima, T., Honda, Y., Kitao, O., Nakai, H., Vreven, T., Montgomery Jr. J.A., Peralta, J.E., Ogliaro, F., Bearpark, M.J., Heyd, J., Brothers, E.N., Kudin, K.N., Staroverov, V.N., Kobayashi, R., Normand, J., Raghavachari, K., Rendell, A.P., Burant, J.C., Iyengar, S.S., Tomasi, J., Cossi, M., Rega, N., Millam, N.J., Klene, M., Knox, J.E., Cross, J.B., Bakken, V., Adamo, C., Jaramillo, J., Gomperts, R., Stratmann, R.E., Yazyev, O., Austin, A.J., Cammi, R., Pomelli, C., Ochterski, J.W., Martin, R.L., Morokuma, K., Zakrzewski, V.G., Voth, G.A., Salvador, P., Dannenberg, J.J., Dapprich, S., Daniels, A.D., Farkas, O., Foresman, J.B., Ortiz, J.V., Cioslowski, J., Fox, D.J., Gaussian 09, 2009, Gaussian, Inc., Wallingford, CT, USA.

46. Macrae, C. F., Bruno, I. J., Chisholm, J. A., Edgington, P. R., McCabe, P., Pidcock, E., Rodriguez-Monge, L., Taylor, R., van de Streek, J. and Wood, P. A., Mercury CSD 2.0 - 
New features for the visualization and investigation of crystal structures J. Appl. Cryst. 2008, 41, 466-470.

47. Cherukuvada, S. and Guru Row, T. N. Comprehending the formation of eutectics and cocrystals in terms of design and their structural interrelationships, Cryst. Growth Des. 2014, 14, 4187-4198.

48. Agrawal, T.; Gupta, P.; Das, S. S.; Gupta, A. and Singh, N. B. Phase equilibria, crystallization, and microstructural studies of naphthalen-2-ol +1 , 3-dinitrobenzene, $J$. Chem. Eng. Data 2010, 55, 4206-4210.

49. Steed, J. W., The role of co-crystals in pharmaceutical design, Trends Pharmacol. Sci. 2013, 34 (3), 185-193. 
Figures

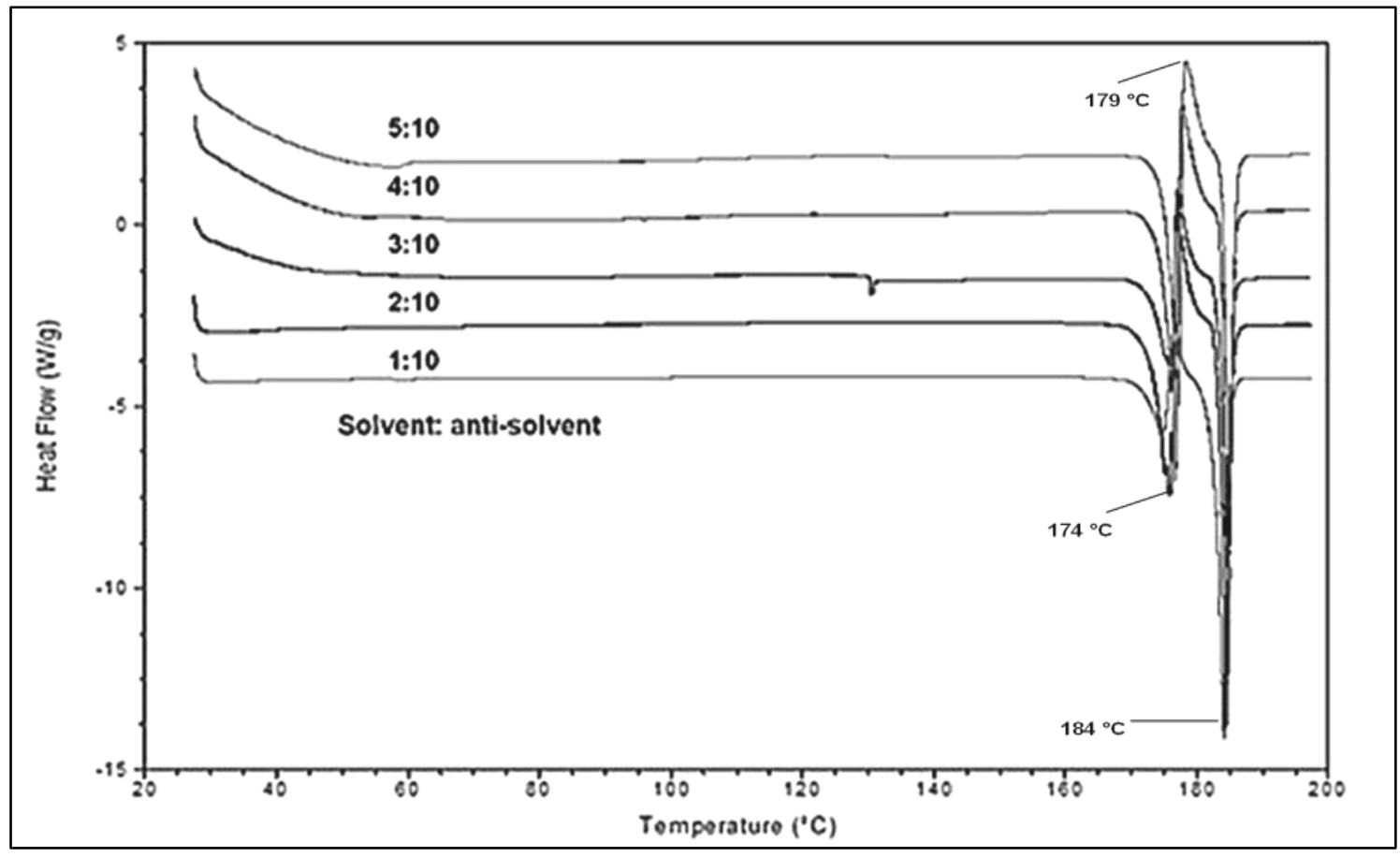

(a)

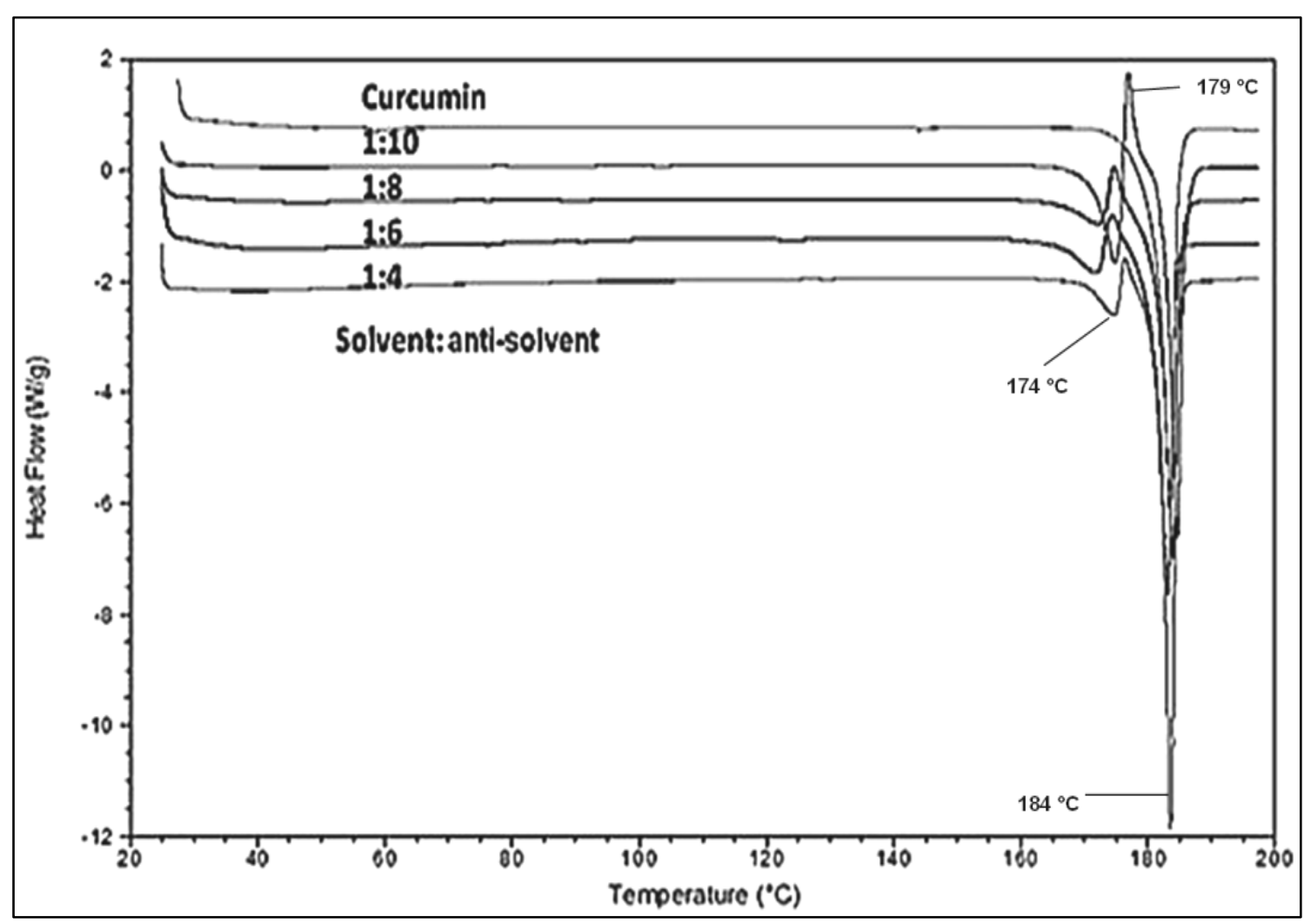

(b)

Figure 1 DSC showing effect of (a) increase in good solvent keeping volume of antisolvent constant (b) increase in anti-solvent keeping volume of good solvent constant 


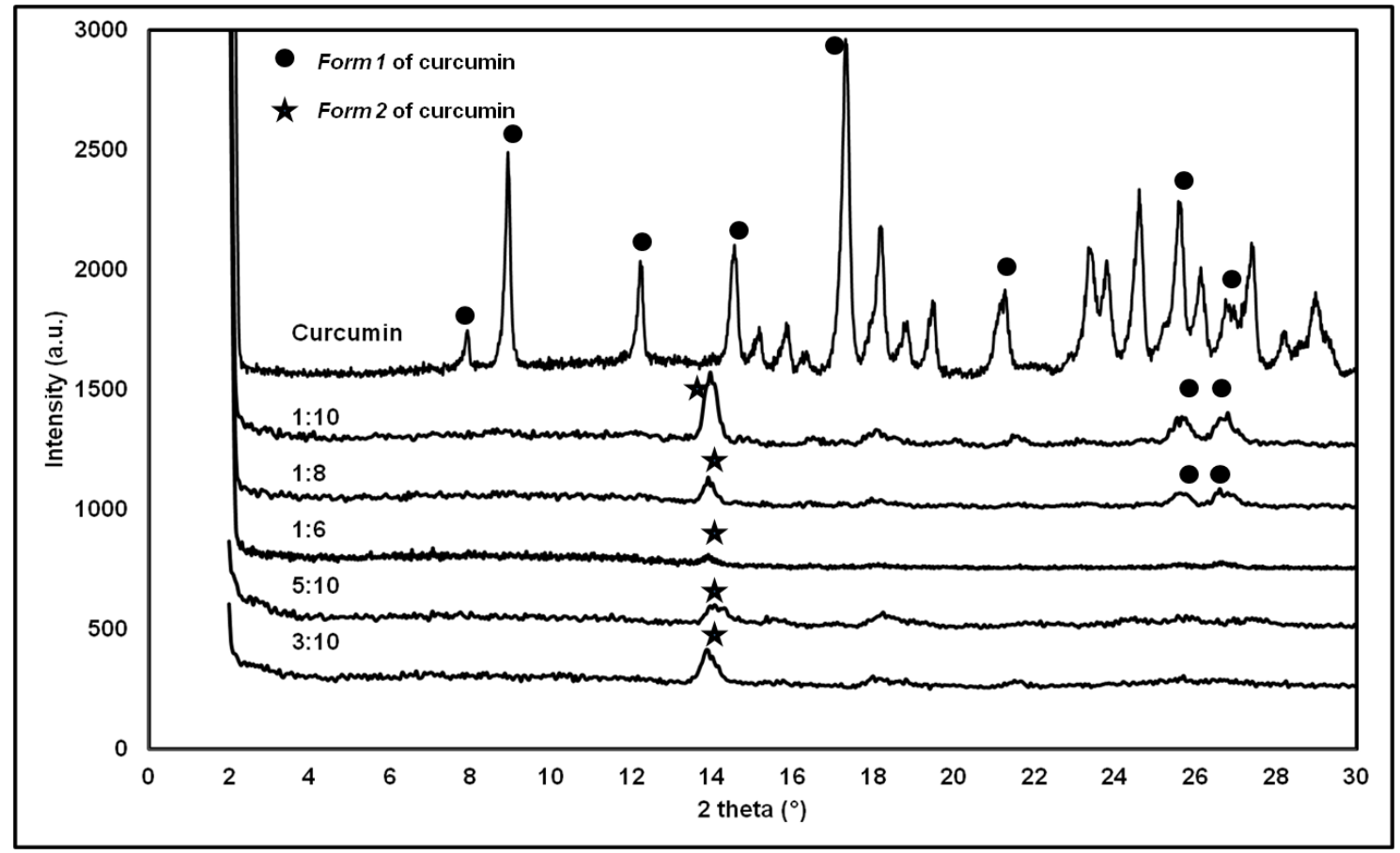

Figure 2 p-XRD showing the comparison plot of varying ratios of solvent: antisolvent 


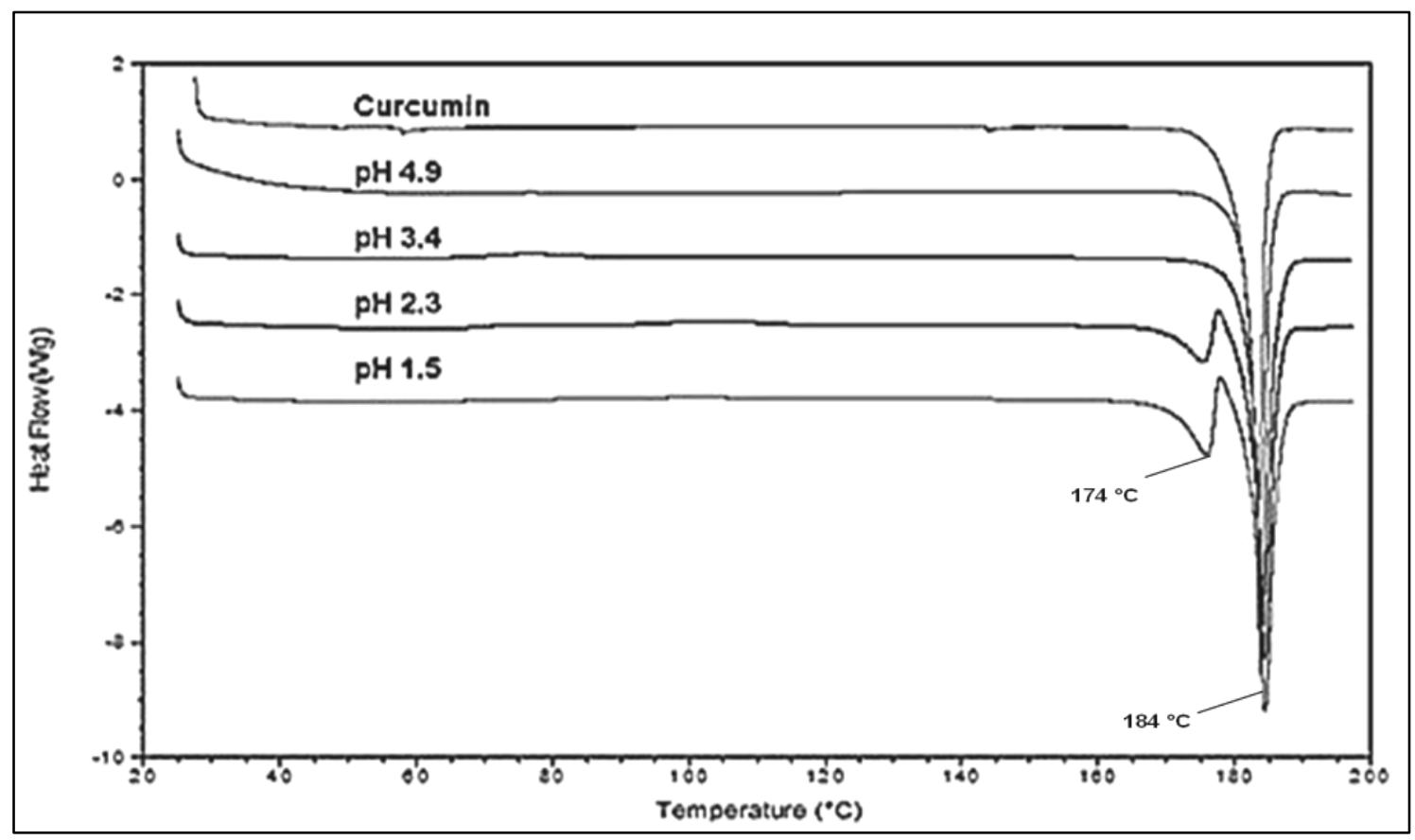

(a)

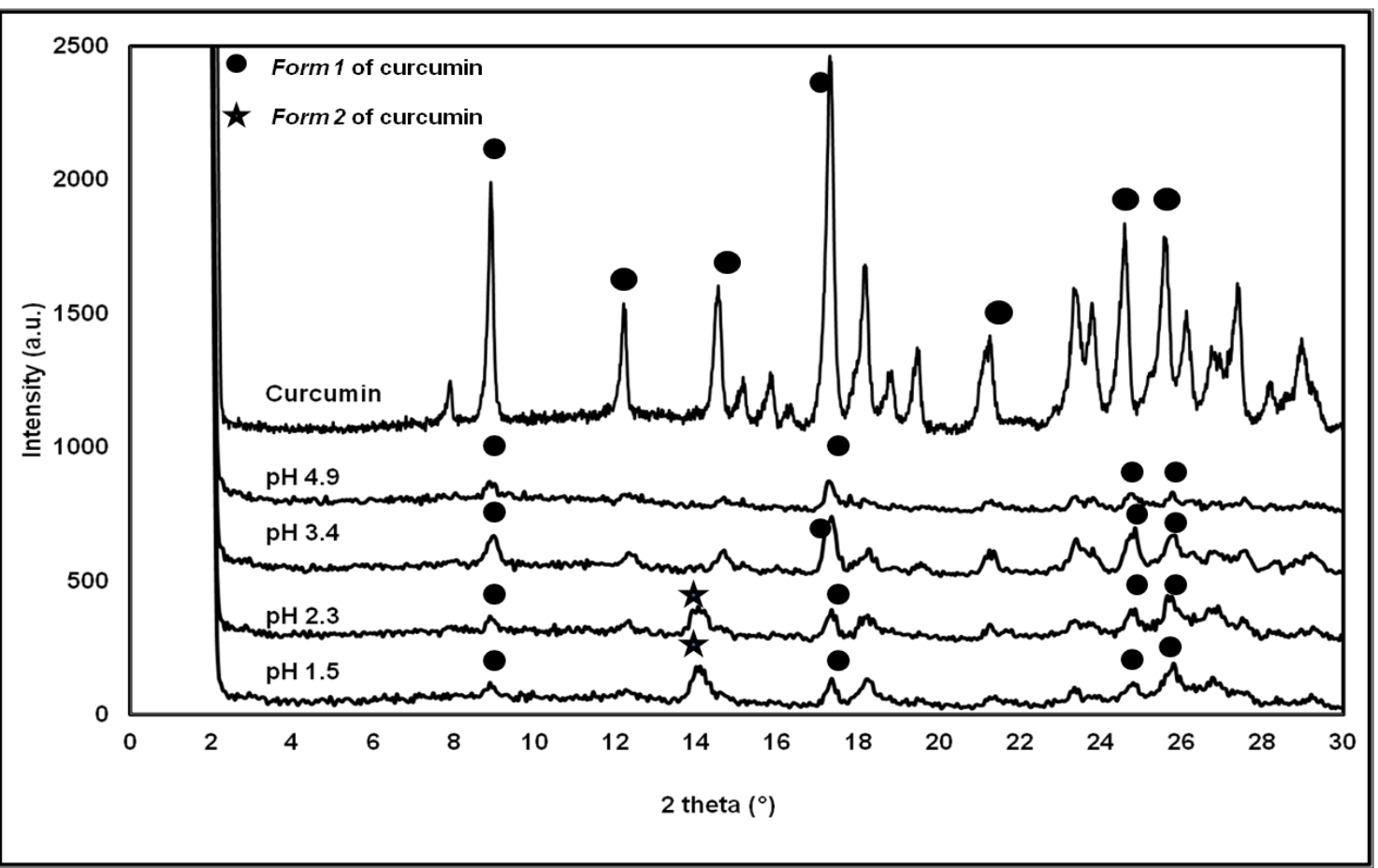

(b)

Figure 3 (a) DSC plot (b) p-XRD plot for 3:10 solvent to anti-solvent ratio with varying $\mathrm{pH}$ of anti-solvent 

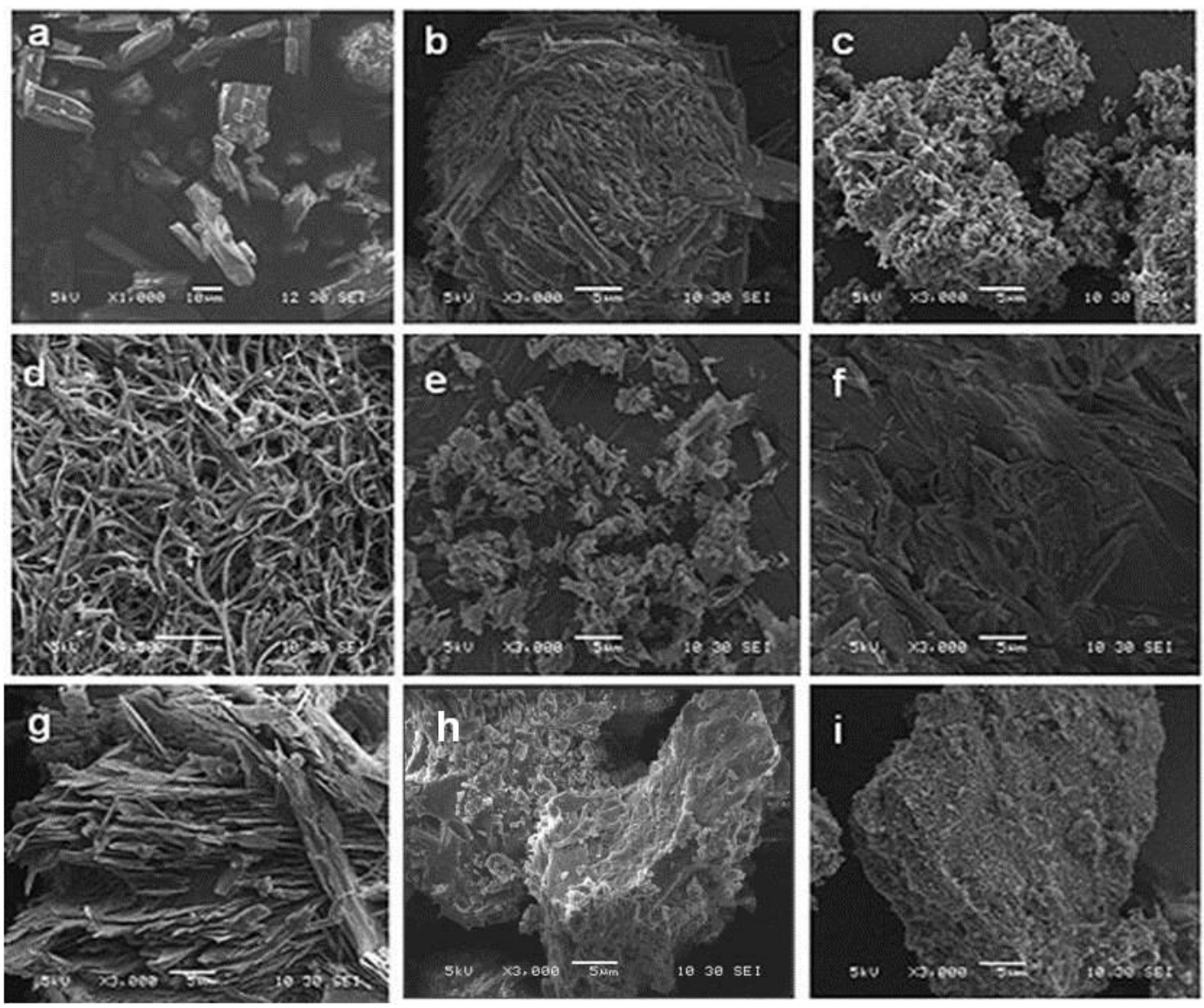

Figure 4 SEM images of (a) Curcumin and (b) the polymorphs of curcumin precipitated by anti-solvent precipitation method with acetone: water ratio as 1:10 (c) 2:10 (d) 3:10 (e) 4:10 (f) 5:10 (g) 1:4 (h) 1:6 (i) 1:8
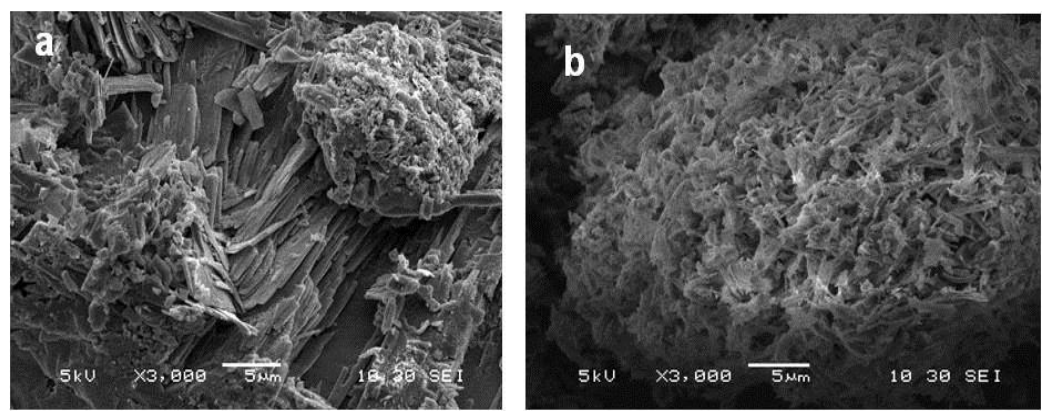

Figure 5 SEM images of the polymorphs of curcumin precipitated by anti-solvent precipitation method with acetone: water ratio as 3:10 with (a) $1.5 \mathrm{pH}$ of water (b) $2.3 \mathrm{pH}$ of water 

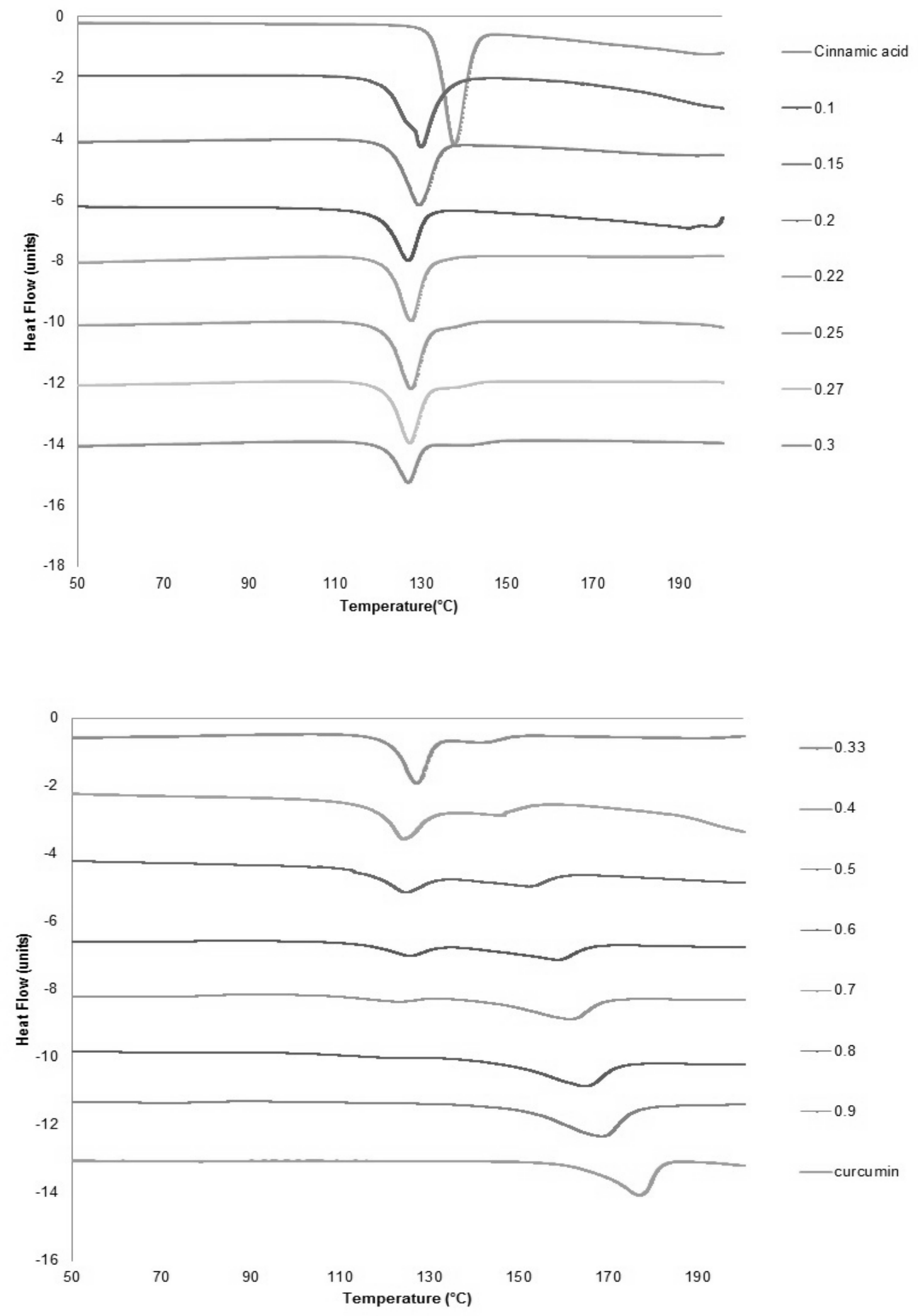

Figure 6 DSC for varying mole fractions of curcumin in various physical mixtures of curcumin and cinnamic acid 


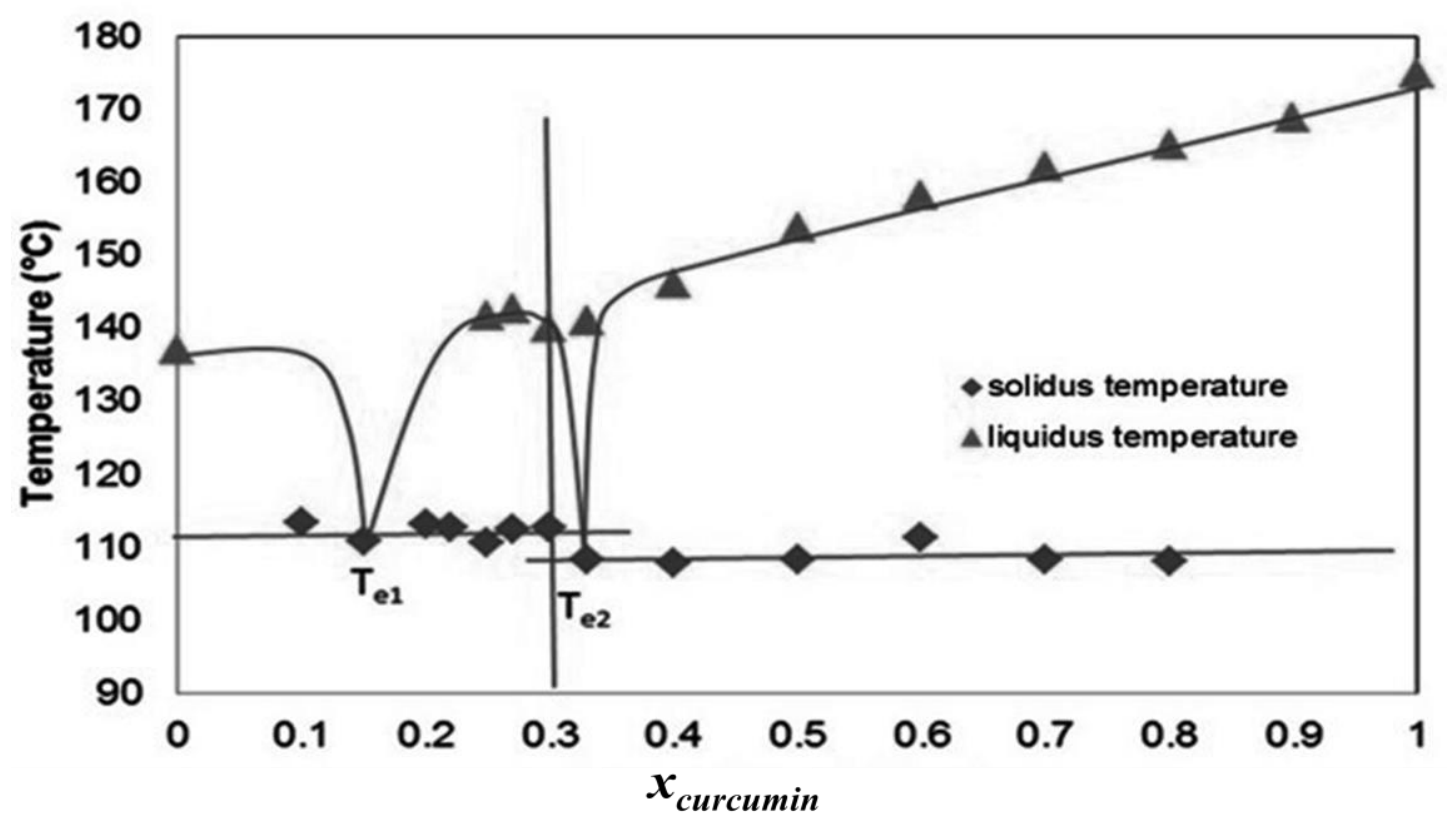

Figure 7 Binary phase diagram of curcumin-cinnamic acid system showing the solidus (squares) and the liquidus (diamonds) temperatures. 


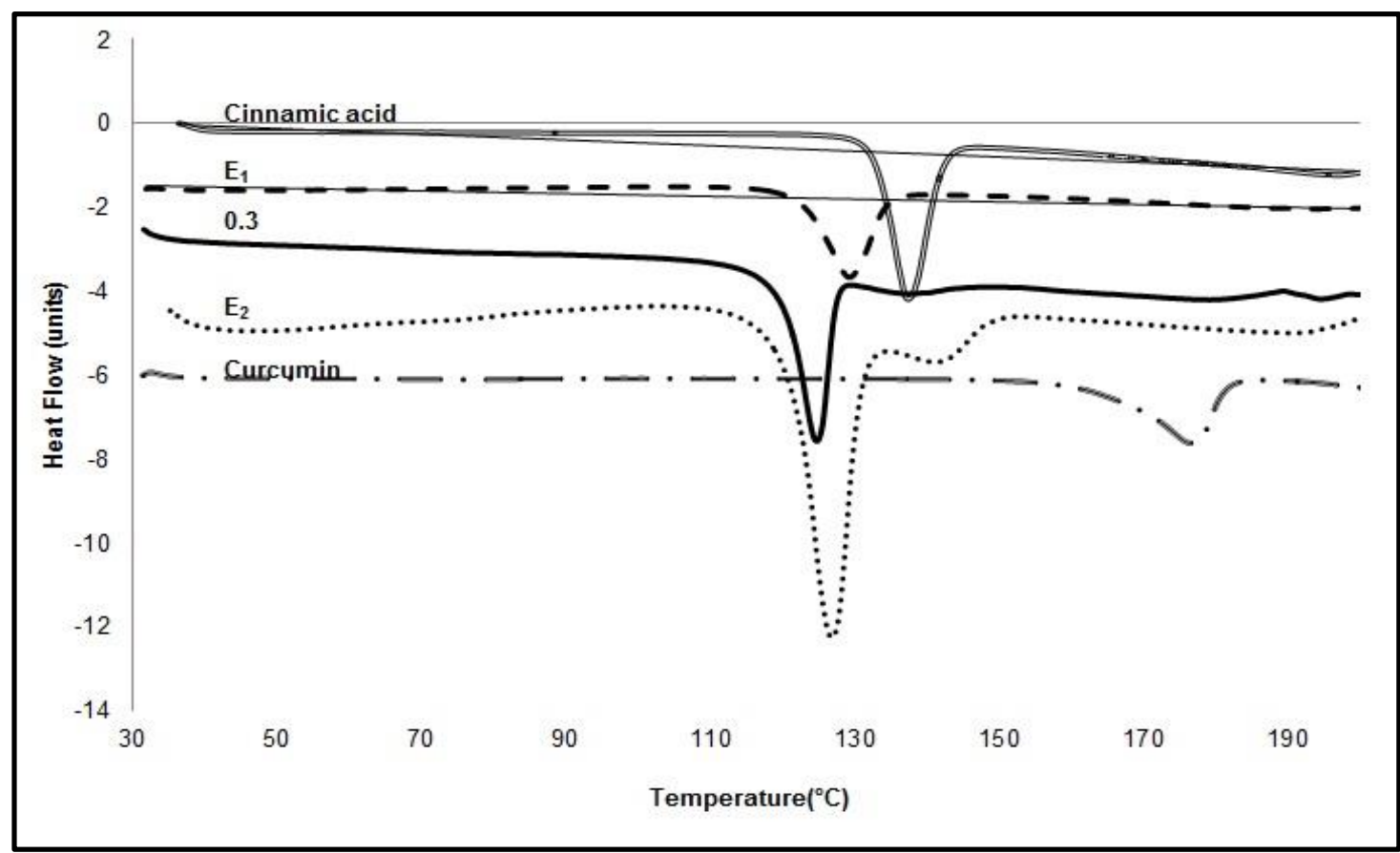

(a)

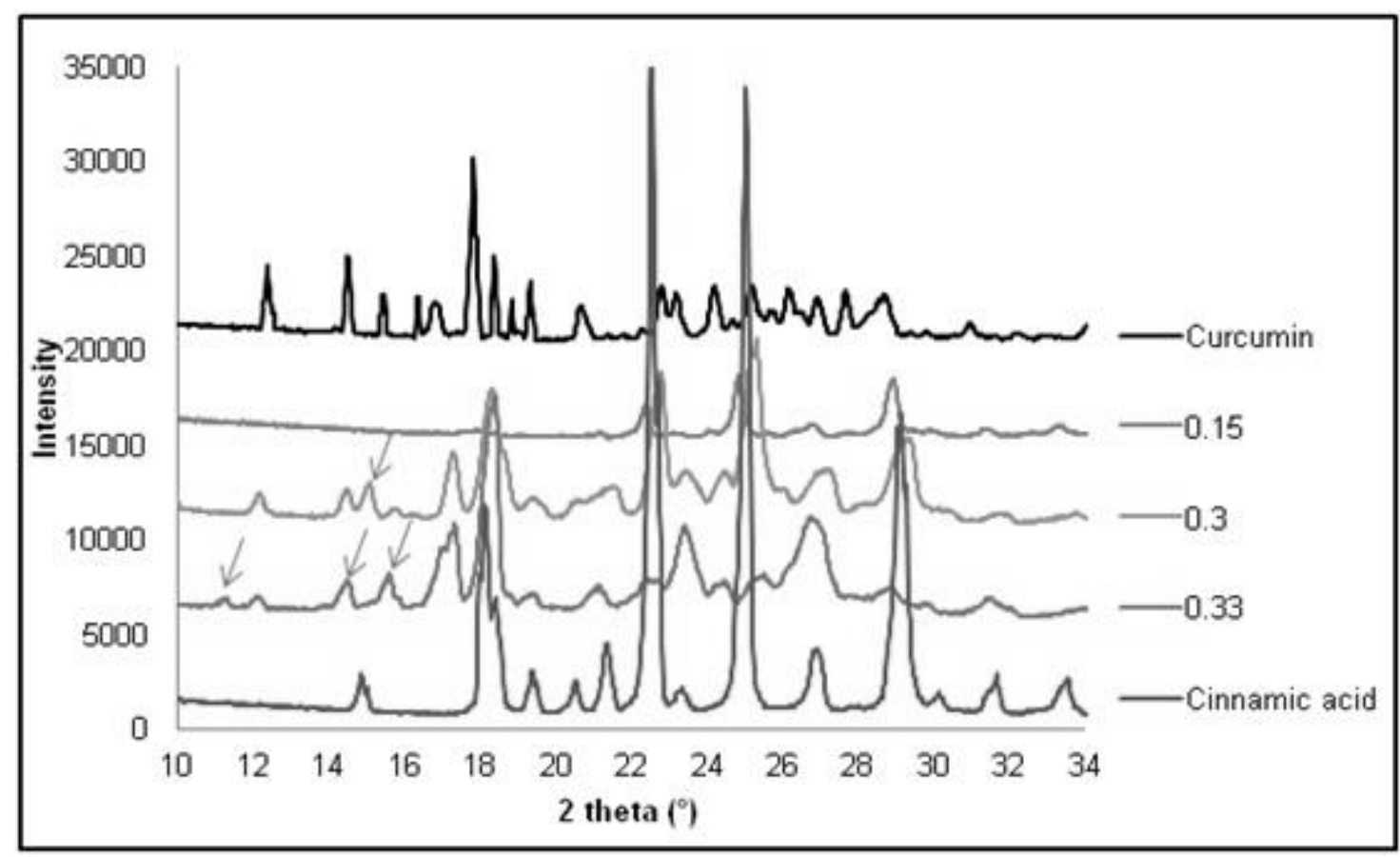

(b)

Figure 8 (a) DSC results of curcumin-cinnamic acid system showing 1:3 co-crystal and 1:2 eutectic (b) p-XRD for the co-crystal system of curcumin-cinnamic acid 


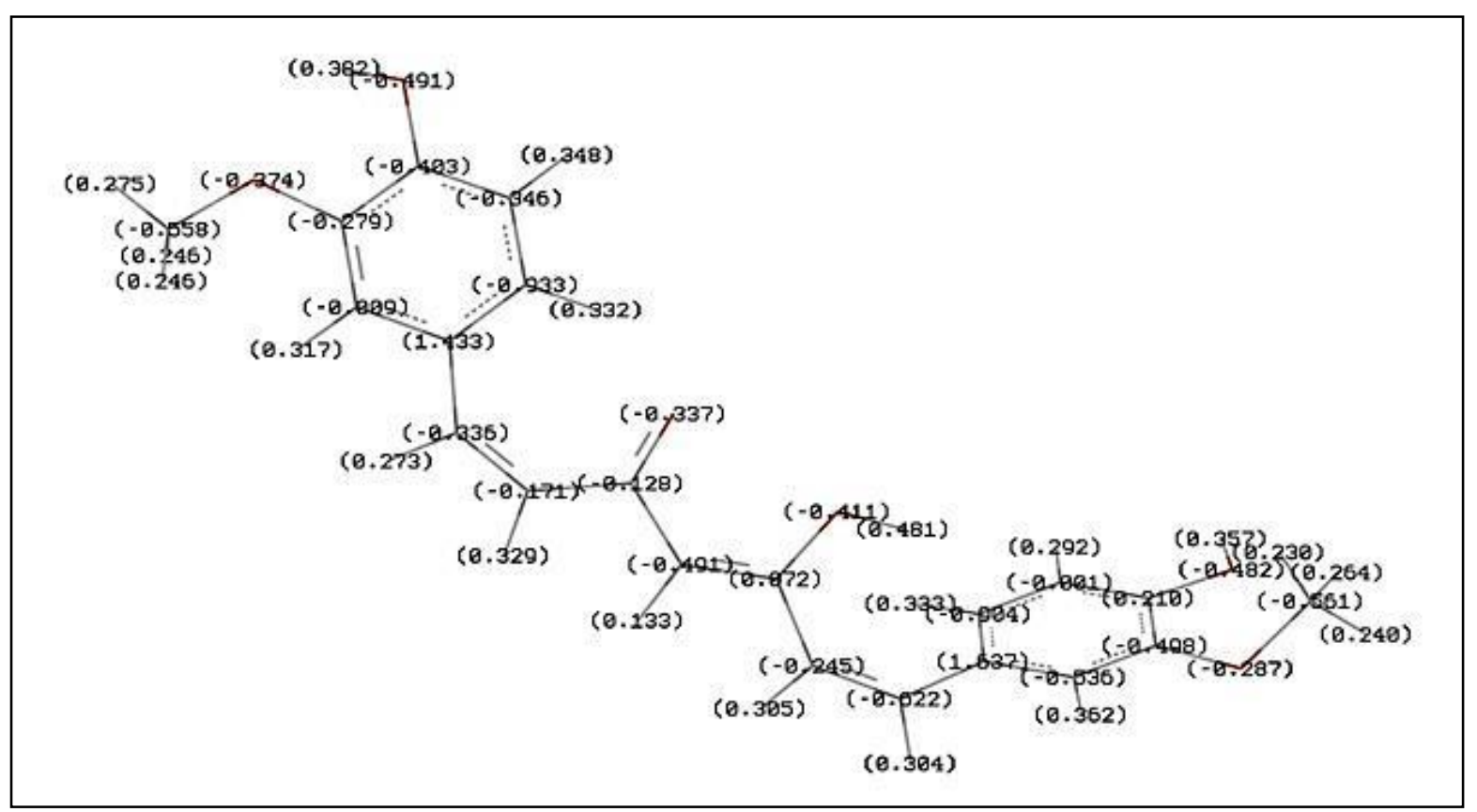

(a)

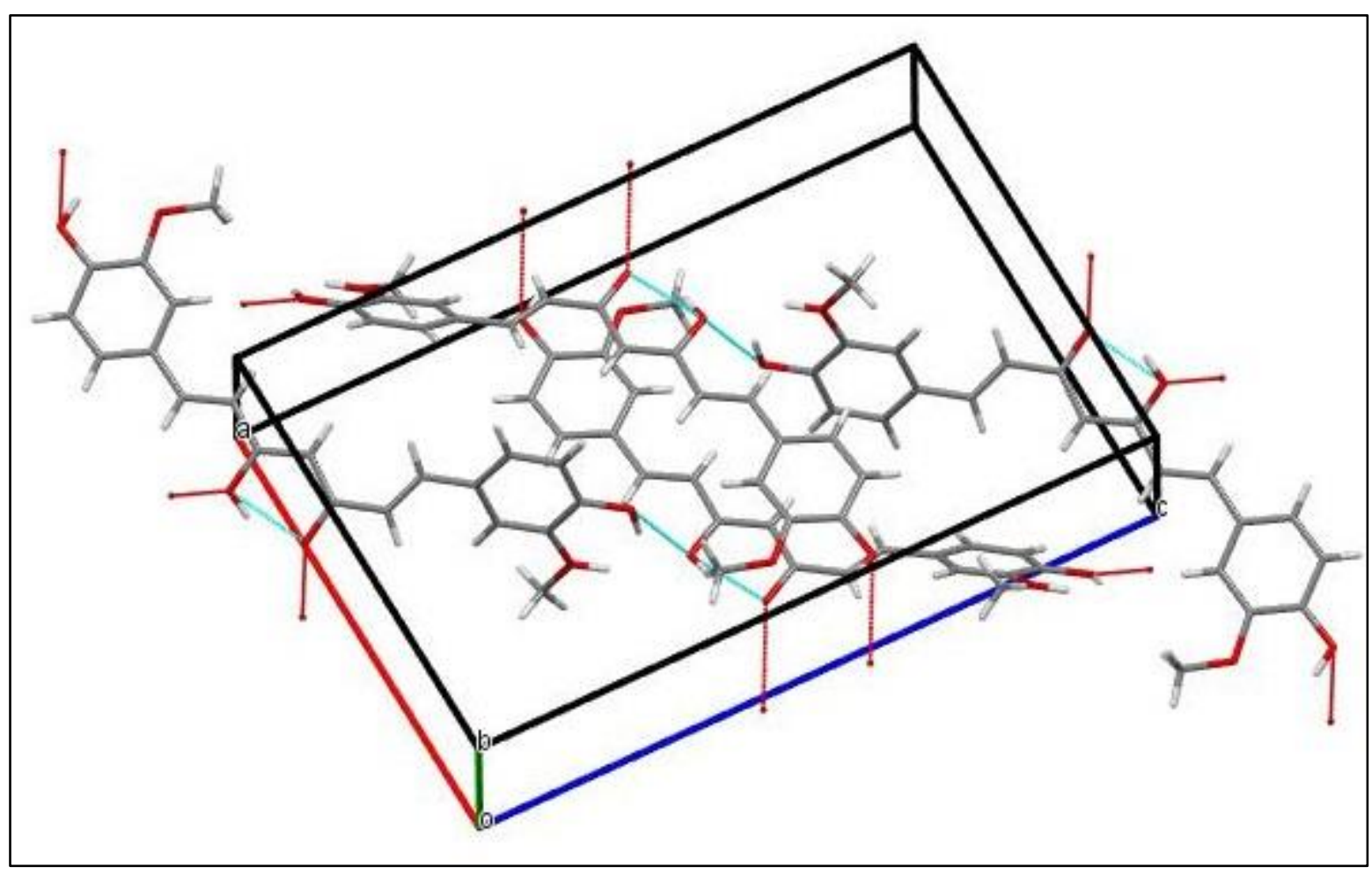

(b) 


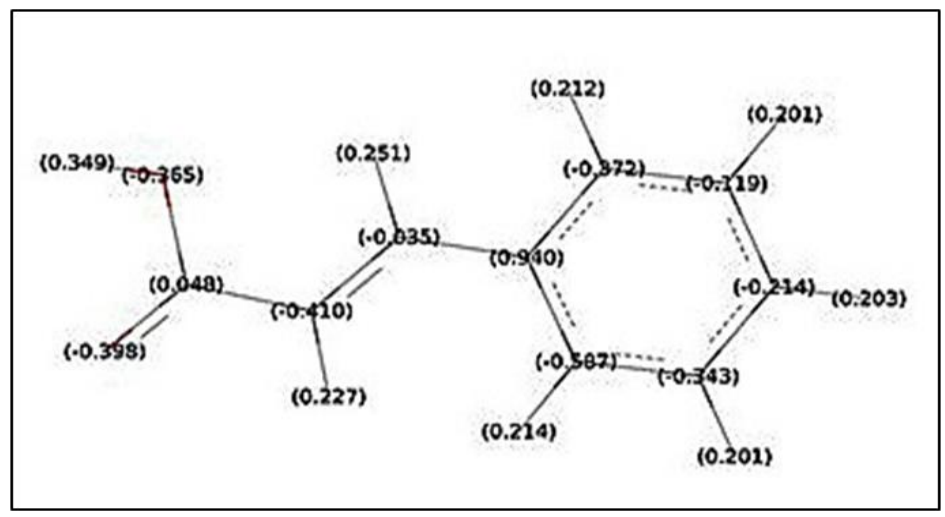

(c)

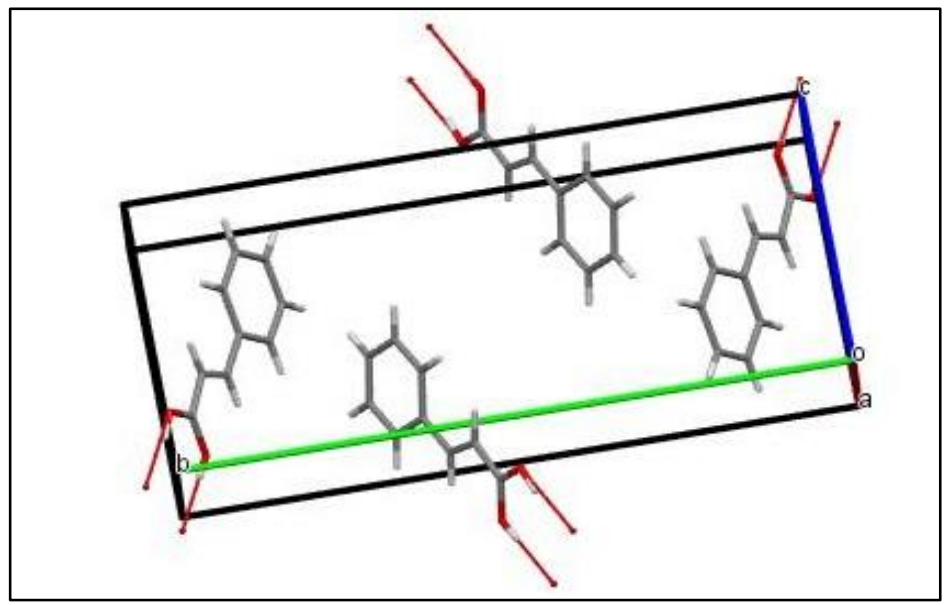

(d)

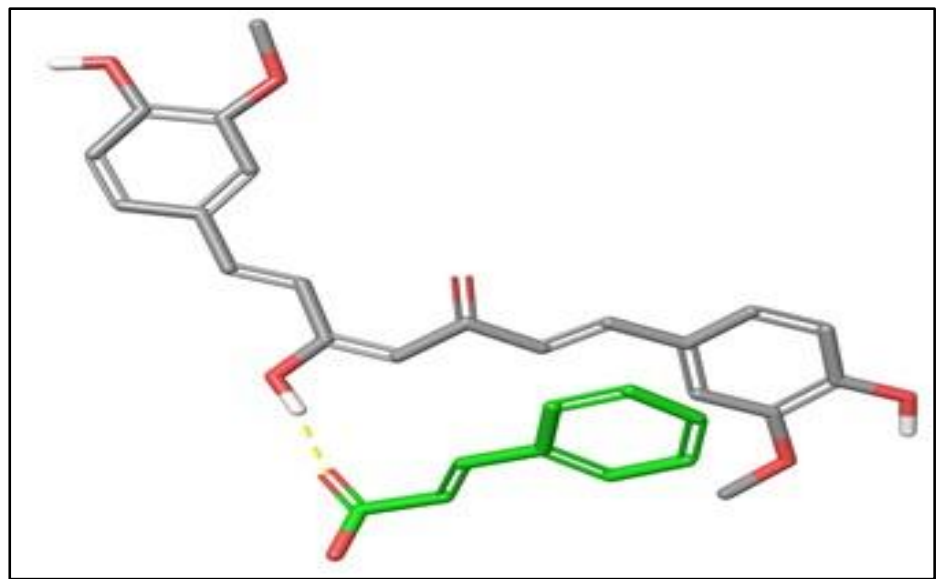

(e)

Figure 9 Optimized chemical structures and crystal packing structures of a unit cell of $(a, b)$ curcumin $(c, d)$ cinnamic acid (e) possible interactions occurring in the co-crystal of curcumin and cinnamic acid

Light blue: intramolecular hydrogen bonding

Red: available sites for intermolecular hydrogen bonding 

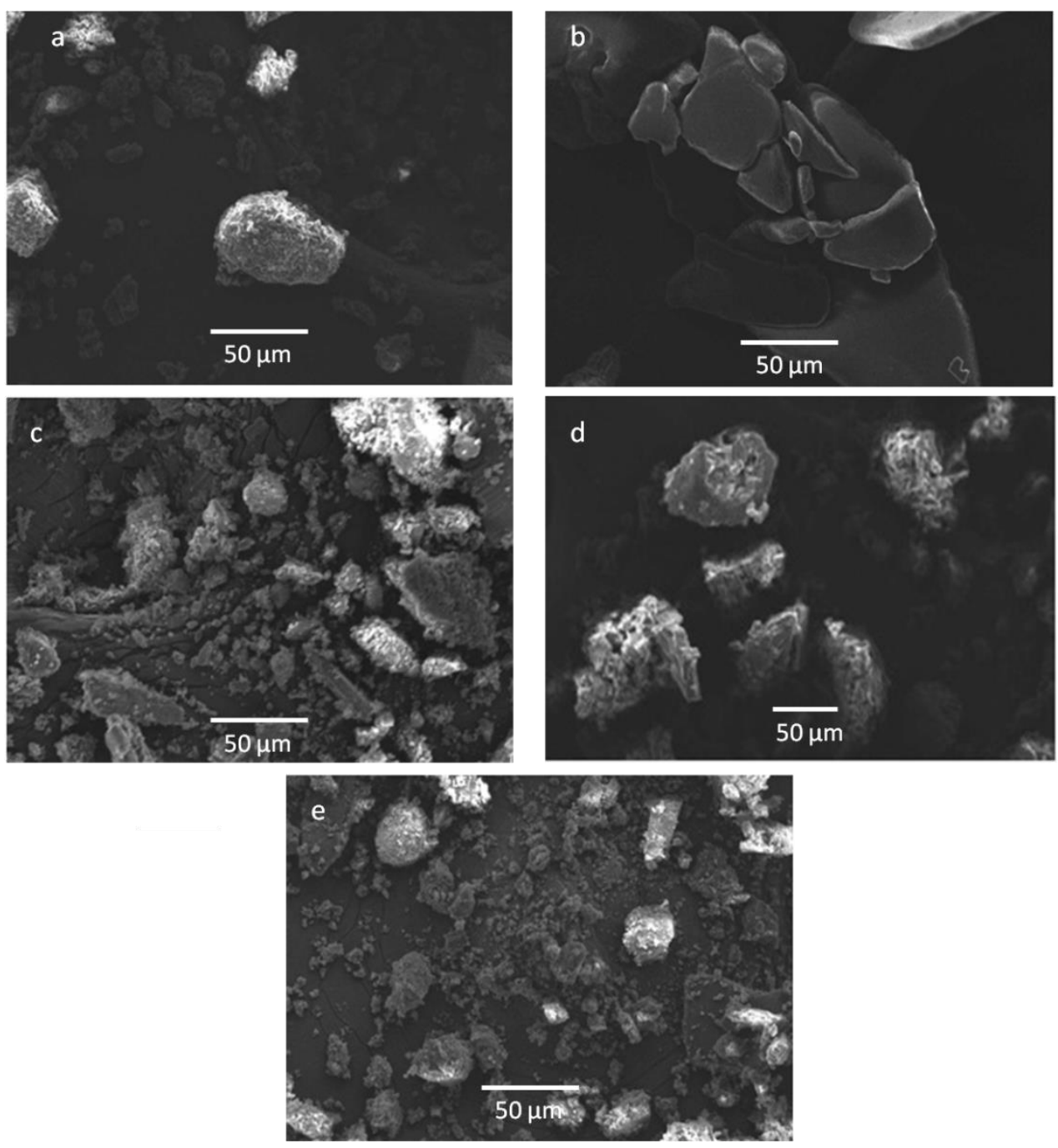

Figure 10 SEM images of (a) Curcumin (b) Cinnamic acid (c) 0.15 curcumin: cinnamic acid eutectic (d) 0.3 curcumin: cinnamic acid co-crystal (e) 0.33 curcumin: cinnamic acid eutectic 
Polymorphic, eutectics and co-crystal studies on Curcumin

Noopur Rathi*, Anant Paradkar\# and Vilas G. Gaikar*

\section{Supplementary Information}

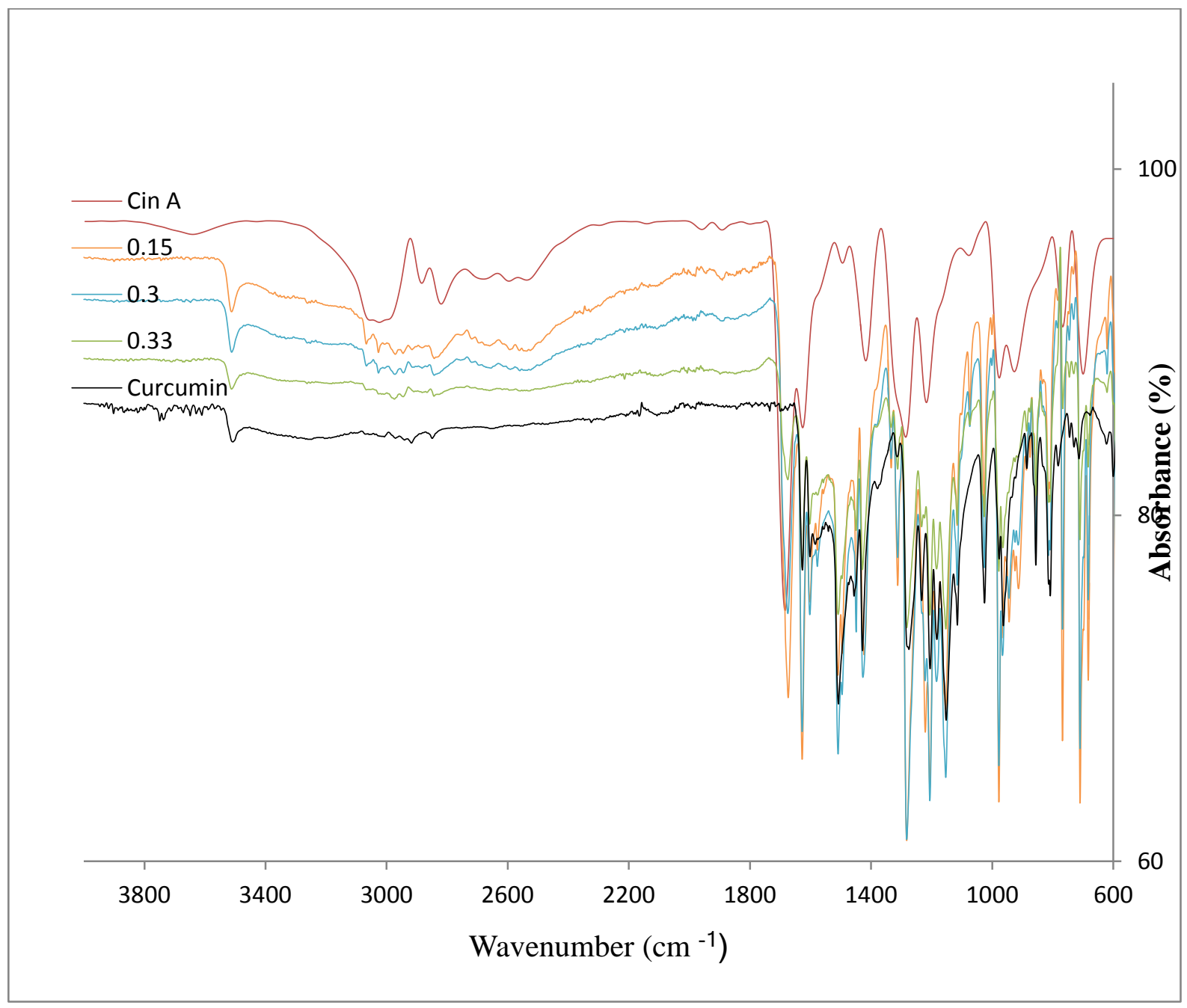

Figure S1 FTIR peaks for Curcumcin, cinnamic acid and there eutectics and co-crystal 